Viso - Cadernos de estética aplicada Revista eletrônica de estética

ISSN 1981-4062

NNo 8, jan-jun/2010

http://www.revistaviso.com.br/

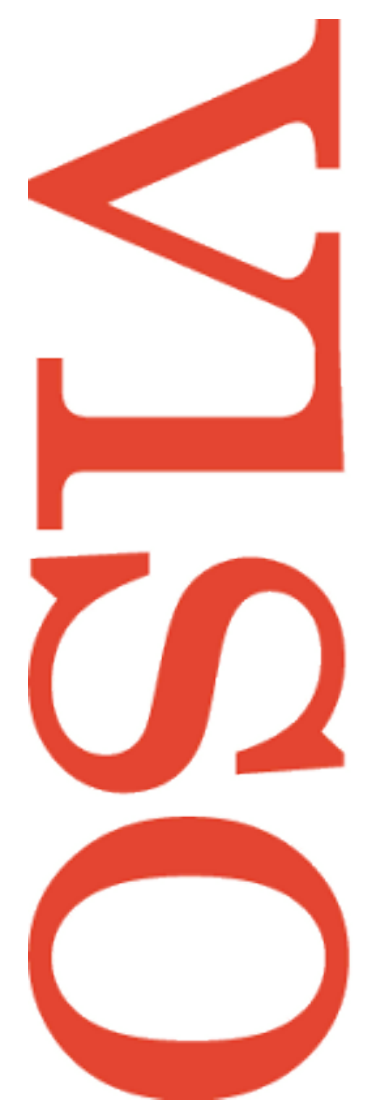

\title{
Arte como ética. Por uma estética da produção. Breve reflexão spinozista. Lorenzo Vinciguerra
}




\section{RESUMO}

Arte como ética. Por uma estética da produção. Breve reflexão spinozista. Este ensaio propõe que haveria em Spinoza elementos para pensar uma estética da produção e questiona o privilégio quase absoluto das estéticas da recepção na atualidade. O texto defende que um retorno ao spinozismo, portanto a um momento anterior ao da fundação da estética como disciplina filosófica autônoma, pode ajudar a superar algumas das aporias da estética na contemporaneidade, tais como a que envolve a definição de arte e os limites e tarefas da crítica.

Palavras-chave: Spinoza - estética da produção - estética da recepção

\section{ABSTRACT}

Art as ethics. Towards aesthetics of production. A brief Spinozist reflection

This paper claims that there are elements in Spinoza which point towards the possibility of an aesthetics of production which challenges the major role played by aesthetics of reception in contemporary thinking. It is suggested that a return to Spinozism, hence to a moment prior to the foundation of aesthetics as an autonomous branch of philosophical investigation, may help solve a few problems in contemporary aesthetics, such as the definition of art and the role and limits of art criticism.

Keywords: Spinoza - aesthetics of production - aesthetics of reception 


\section{VINCIGUERRA, L. "Arte como ética. Por uma estética da produção. Breve reflexão spinozista". In: Viso: Cadernos de estética aplicada, v. IV, n. 8 (jan-jun/2010), pp. 1-9.}

DOI: $10.22409 / 1981-4062 / v 8 i / 81$

Aprovado: 16.01.2010. Publicado: 10.07.2010.

(C) 2010 Lorenzo Vinciguerra. Esse documento é distribuído nos termos da licença Creative Commons Atribuição-NãoComercial 4.0 Internacional (CC-BY-NC), que permite, exceto para fins comerciais, copiar e redistribuir o material em qualquer formato ou meio, bem como remixá-lo, transformá-lo ou criar a partir dele, desde que seja dado o devido crédito e indicada a licença sob a qual ele foi originalmente publicado.

Licença: http://creativecommons.org/licenses/by-nc/4.0/deed.pt_BR

Accepted: 16.01.2010. Published: 10.07.2010.

(C) 2010 Lorenzo Vinciguerra. This document is distributed under the terms of a Creative Commons Attribution-NonCommercial 4.0 International license (CC-BY-NC) which allows, except for commercial purposes, to copy and redistribute the material in any medium or format and to remix, transform, and build upon the material, provided the original work is properly cited and states its license.

License: http://creativecommons.org/licenses/by-nc/4.0/ 
Qui [...] credunt, se ex libero Mentis decreto loqui, vel tacere, vel quicquam agere, oculis apertis somniant. ${ }^{1}$

Haveria um evidente anacronismo em querer buscar em Spinoza um equivalente disso que nós, herdeiros de Baumgarten, Kant e do idealismo alemão, chamamos hoje de estética ou filosofia da arte. Como na maior parte de seus contemporâneos, não há, não pode haver estética em Spinoza, ao menos no sentido que esse termo acabou assumindo para nós.

Os textos oferecem, no entanto, de modo farto, matéria para uma reflexão sobre a arte. ${ }^{2}$ $\mathrm{O}$ valor deles nos parece interessante hoje em dia, em uma época na qual, fortemente abalada pelas revoluções artísticas do século $X X$, a estética atravessa uma crise profunda. $\mathrm{O}$ anacronismo do spinozismo poderia então se mostrar como possuindo uma certa utilidade e uma certa atualidade inesperada, para compreender o que se pode entender por arte.

\section{Os sentidos da palavra ars}

Em Spinoza, o termo ars designa mais freqüentemente uma técnica (inata ou aprendida) e sua mestria. Às vezes compreendida como "capacidade de tornar fácil o que é difícil" ${ }^{3}$, ele designa um saber fazer ou, ligado à noção de faber, fabrica, fabricari, um saber produzir, remetendo à noção de ingenium. ${ }^{4} \mathrm{~A}$ esse respeito, as produções artificiais ou artísticas não são opostas às produções naturais; elas não constituem um império no império das produções da natureza; não se deve, portanto, opô-las e privilegiar umas em relação às outras como o faz Hegel, que considerava as primeiras, enquanto manifestação do espírito, superiores às segundas.

Considerações estéticas sobre as artes são, no entanto, mais raras no corpus spinoziano. A música é dita "boa para o melancólico, má para o aflito e nem boa nem má para o surdo". ${ }^{5}$ Além disso, essas afirmações se inscrevem mais no quadro de uma medicina que de uma estética stricto sensu. Spinoza jamais discute as teorias estéticas de sua época (Vossius, Bellori). Ele não estabelece nenhuma diferença entre as próprias artes; ele não se interessa pela sua classificação ou pela sua hierarquia; as artes liberais não são opostas às artes mecânicas.

Uma estética das obras de arte não é muito desenvolvida. Há muitas referências, por exemplo, ao retrato, aos edifícios, às pinturas, mas o contexto argumentativo não é estético no sentido de que as artes teriam por objeto encarnar a ideia do belo. Por outro lado, é precisamente sobre o problema da beleza (natural ou artificial), em sua correspondência com Boxel e na Ética, que sua crítica a toda substancialização e 
ontologização do belo torna-se radical. Ela se confunde com a crítica do finalismo e de toda tendência demasiado humana em querer "estetizar" a natureza como criação de um Deus-arquiteto ou a divinizar o artista quanto à sua liberdade de criação. Sobre este ponto, uma crítica à estética neoplatônica está contida in nuce desde o Tractatus de intellectus emendatione, $\S 60$, quando Spinoza denuncia aqueles que pensam que a alma pode criar apenas com sua força das sensações, ou das ideias que não são coisas; de tal modo que eles a consideram, em parte, como um Deus.

Vale, portanto, para a beleza e a feiúra, o que vale para noções tais como "perfeição", "bem", "ordem", "mérito", e seus contrários. Elas não permitem conhecer nada das coisas mesmas, sendo apenas uma certa maneira de imaginar. A noção de beleza é rebaixada a uma explicação de tipo fisiológica:

Se o movimento que recebem os nervos a partir dos objetos que se representam pelos olhos contribui para a saúde, os objetos que o causam são ditos belos, e aqueles que excitam um movimento contrário, feios. ${ }^{6}$

A beleza para a imaginação visual é tratada do mesmo modo que a harmonia para a imaginação auditiva. De modo que, se quiséssemos, a qualquer preço, encontrar uma estética do gosto no spinozismo, esta não ultrapassaria o relativismo fisiológico expresso pela máxima: quot capita, tot sensus (cada cabeça, uma sentença), origem de muitas controvérsias, como o diz Spinoza e finalmente o Ceticismo. Pode-se observar, no entanto, que esse relativismo se apoia, não obstante, como é o caso para a música, sobre a questão da saúde do corpo.

A esta constatação devem seguir-se algumas observações: quando Spinoza se instala em Voorburg, é na casa do pintor Daniel Tydeman que ele vai morar. É ainda na casa de um pintor, Hendryck van der Spyck, que irá viver em La Haye. Esta arte indiferente à orelha the assegurará sem dúvida a calma necessária ao estudo e à escrita. Após ter-se aperfeiçoado na arte mecânica do polimento dos vidros de lentes, nos diz Colerus, "ele se interessou pelo desenho, que ele aprendeu sozinho", e particularmente pela arte do retrato. ${ }^{7}$ Amante de teatro e de perfumes, no contato cotidiano com pintores, Spinoza se dedicou à arte do desenho.

O interesse spinozista pela arte é, portanto, antes de tudo, prático. Ora, essa prática nos parece confundir-se com o projeto ético spinozista e sua realização da vida feliz. Podemos encontrar suas linhas teóricas na Ética.

\section{Ars corporis}

A cada vez que os textos fazem referências à arte e a suas obras, como é o caso no Apêndice da primeira parte da Ética, e sobretudo na Ética, III, 2, scholium, a questão essencial trata das relações entre o espírito e o corpo. No escólio, escrito como reforço 
do teorema que afirma que o corpo não pode determinar o espírito a pensar, nem o espírito determinar o corpo ao movimento e ao repouso, Spinoza faz mais do que em outros lugares referência às obras de arte: aedificiorum, picturarum, rerumque hujusmodi. Estas produções se fazem apenas pela arte dos homens [sola arte humana fiunt] e a causa delas deve ser buscada no Corpo Humano sem nenhuma interação com o Espírito, como o faríamos para explicar os gestos de um sonâmbulo.

Tal é a via que é preciso seguir para compreender a originalidade do pensamento de Spinoza sobre a arte em sua época e talvez também na nossa. A arte é em sua essência ars corporis. Ora, enquanto expressão da potência do corpo, a essência da arte não pode ser confundida com suas propriedades miméticas. A imitação da natureza é menos a causa genética da arte que o efeito de práticas historicamente determinadas, como aquelas da pintura holandesa no tempo de Spinoza. ${ }^{8}$ Esta se mede a partir disso que o corpo pode fazer na medida em que ele é considerado causa adequada do que ele produz. A potência do corpo é assim a única causa adequada da arte.

A natureza da arte se situa antes no nível do problema da adequação, isto é, disso que o Corpo pode fazer ex solis legibus ejus naturae. A arte pode ser em geral compreendida como o aspecto corporal de uma ação:

Eu digo que nós agimos quando se faz em nós ou fora de nós algo de que nós somos a causa adequada, isto é, quando de nossa natureza se segue, em nós ou fora de nós, algo que se pode compreender claramente e distintamente por si mesmo. ${ }^{9}$

A ars corporis como potentia corporis é, portanto, uma ars imaginandi, uma vez que concedamos à imaginação a possibilidade de se exercer como virtude, isto é, ativamente e não apenas passivamente. É o que permite entender uma outra passagem da Ética:

Se o Espírito, enquanto imagina ter em sua presença coisas que não existem, ao mesmo tempo soubesse que essas coisas, na verdade, não existem, é claro que ele atribuiria esta potência de imaginar a uma virtude de sua natureza, não a um vício; sobretudo se essa faculdade de imaginar dependesse apenas de sua natureza, isto é, (pela Def. 7, p. 1) se essa faculdade que o Espírito tem de imaginar fosse livre. ${ }^{10}$

O sentido deste texto é freqüentemente considerado como enigmático. Habitualmente, se prefere ler a hipótese da imaginação livre como uma hipótese circa impossibilia. Como, com efeito, conceber uma imaginação livre, já que por definição ela é dita passiva, ao menos se nos limitamos ao Tractatus de intellectus emendatione? ${ }^{11}$ Uma outra leitura é todavia possível: se devemos recusar a ideia de liberdade absoluta à imaginação (a primeira só convém a Deus, enquanto a segunda lhe é estranha), podemos, no entanto, manter aquela de uma liberdade da imaginação diretamente proporcional à potência do corpo que a exerce. É, aliás, o sentido que ganhará o fim do escólio citado, que sublinha a positividade da imaginação e, portanto, a possibilidade, para ela, de ser não apenas viva, mas também ativa. 
Nesse sentido, a arte, como arte do corpo, é uma arte da imaginação, pela qual o corpo passa a uma potência maior, transformando sua passividade nativa em atividade ao menos parcial. A arte é, portanto, a determinação do corpo a uma certa autonomia prática, que o promove a uma maior perfeição. Enquanto alegria, o trabalho artístico [fabricari] é este espaço onde o corpo se dá os meios de um livre jogo de seu ingenium. A arte está, portanto, antes de tudo na maneira, antes mesmo de dever ser julgada por seus resultados.

As artes, consideradas ao mesmo tempo do ponto de vista de sua prática, de seu exercício lúdico [ludis exercitatoriis] e de sua fruição constituem assim os verdadeiros alimentos do corpo, cuja vida não pode se reduzir apenas à circulação do sangue. ${ }^{12}$ Podemos também compreender que a saúde do corpo social passa pelo livre desenvolvimento das ciências e das artes, as únicas habilitadas a dar uma realidade efetiva à liberdade humana.

Se as artes resultam apenas das leis do corpo, não se pode encarregar a arte da questão da verdade, como foi freqüentemente feito no século $X X$ seguindo nisso a estética heideggeriana. Para Spinoza, com efeito, a verdade se diz das idéias, não dos corpos. Assim como a definição adequada em Spinoza não coloca em primeiro lugar a questão da verdade no sentido extrínseco do termo, mas a da potência e de sua verdade intrínseca (a definição não é adequada porque verdadeira, mas verdadeira porque adequada), da mesma forma, pode-se dizer que a essência da arte reside apenas na potência do corpo ou da imaginação e das leis que daí derivam.

O sentido de uma tal crítica, no entanto, não tem por efeito separar a arte da filosofia ao ponto de torná-las estranhas uma à outra, mas, antes, de salvaguardar uma e outra em sua direção, cada uma permanecendo, por assim dizer, livre em seu domínio, embora saídas juntas de uma só e mesma potência, a do conatus. Como outrora Spinoza separou teologia e filosofia para torná-las independentes uma frente à outra, relido hoje em dia, o spinozismo parece em condições de separar a estética da filosofia sem subordinação de uma à outra.

A partir de então, assim como a arte se compreende totalmente pela potência genética do corpo, a filosofia está inteiramente compreendida na potência do espírito. A esse respeito, podemos considerar o método geométrico adotado pela filosofia como esta arte que a razão exerce para conduzir da melhor forma a imaginação segundo a norma do entendimento.

\section{Aesthetica sive ethica}

O pensamento não estético de Spinoza nos parece hoje mais do que nunca interessante num tempo em que reina um ceticismo e um relativismo difuso quanto à possibilidade de uma definição, mesmo que mínima, da arte. Uma abordagem de tipo spinozista pode nos 
ajudar não apenas a assumir esta crise, a dissipar os discursos sobre o declínio da arte, sobre seu fim pressuposto ou sua morte anunciada, mas também a nos fazer compreender as suas razões.

O que é a arte? Eis aí uma questão que inquieta grande número de artistas e de filósofos no século XX. Arthur Danto mal se dá conta de quão bem ele identifica o problema, quando ele escreve, por exemplo:

A relação entre a arte e a filosofia é antiga e complexa e [...] eu sou obrigado a reconhecer que sua sutileza é tal que ela transcende talvez nosso poder de descrição analítica, como é o caso na relação entre o espírito e o corpo: é longe de ser evidente que se possa separar a arte da filosofia, já que a substância da arte é em parte constituída por aquilo que se acredita filosoficamente que ela é. ${ }^{13}$

Para distinguir arte e filosofia sem, no entanto, ter que separá-las radicalmente, seria preciso uma filosofia em condições de compreender adequadamente a relação entre o espírito e o corpo. Se tantas polêmicas afligiram o pensamento contemporâneo sobre a arte, é em razão não apenas das reviravoltas históricas que afetaram as práticas artísticas, mas também e, sobretudo, em razão de confusões filosóficas no que concerne à potência do espírito e à do corpo.

Deste ponto de vista, o spinozismo oferece uma base de resposta, mínima talvez, mas ainda assim uma base, para o problema da essência da arte. Ela permite sustentar os dois chifres do dilema no qual se fechou o pensamento contemporâneo, aprisionado entre os defensores de uma definição nominalista (é arte tudo o que chamamos de arte) e os defensores de uma concepção realista de sua essência. Uma abordagem spinozista permite conservar estes dois aspectos ao preço de uma relativização cultural e histórica das artes, de suas hierarquias e de seus gêneros (o que, por outro lado, reflete bastante bem o estado da arte hoje em dia), mas, sobretudo, ao preço de uma refundação da estética na ética, especialmente naquilo que se poderia chamar uma ética do corpo.

Nesse sentido, o spinozismo não tinha nenhuma necessidade de escrever uma estética, pois a experiência estética se encontra inscrita no projeto ético e político, no qual as artes são, com as ciências, como o afirma o Tractatus theologico-politicus, "totalmente necessárias à perfeição da natureza humana e à sua beatitude". ${ }^{14}$ As artes são, portanto, as maneiras, as práticas que o corpo se esforça em pôr em obra apenas pelas leis de sua natureza e de suas técnicas a fim de aumentar sua potência e gozar assim ativamente da eternidade de sua essência. A arte do corpo propriamente falando não está no objeto, nem no sujeito, mas na maneira que tem o corpo de modificar os objetos e de ser modificado por eles no sentido de sua maior potência. A potência do corpo é assim tanto a causa adequada das obras de arte, quanto o efeito da arte que ele põe em obra. Se as artes não são eternas, mas sempre sujeitas em sua forma à história de sua prática, o que é feito com arte aumenta a saúde do corpo e faz a sua salvação, the permitindo gozar de sua eternidade. Nesse sentido, a arte como prática corporal constitui 
a virtude do corpo ativo e realiza uma forma de liberdade própria à imaginação, segundo uma necessidade interna que pertence ao corpo enquanto corpo.

Cultivar a potência do corpo é aumentar a parte eterna do espírito, pois Spinoza escreve em Ética, V, 39:

Quem tem um Corpo apto a um número muito grande de coisas, tem um Espírito cuja maior parte é eterna.

Tudo permite, portanto, crer que nosso sentimento de eternidade é tanto maior quanto mais é desenvolvida uma arte da imaginação própria ao corpo, em condições de exprimir a alegria e a salvação que lhe são próprias. É por isso que não há filosofia sem arte. A arte de pensar [ars excogitandi] ${ }^{15} \mathrm{e}$ a arte de imaginar como arte do corpo constituem em conjunto a arte de viver, o que Spinoza chama de ethica.

\footnotetext{
* Lorenzo Vinciguerra é professor de filosofia na Université de Reims Champagne-Ardenne. ${ }^{1}[\ldots]$

${ }^{2}$ Tal é a opinião, que nós partilhamos, daqueles que quiseram abordar ou tratar desta questão; cf. SCHLERATH, F. Spinoza und die Kunst. Dresden: Hellerau, 1920; DE DEUG, C. The Significance of Spinoza's First Kind of Knowledge. Assen: Van Gorcum, 1966; e, especialmente, MIGNINI, F. Ars imaginandi. Apparenza e rappresentazione in Spinoza. Napoli: Edizioni Scientifiche Italiane, 1981.
}

${ }^{3}$ Tractatus de intellectus emendatione, § 15.

${ }^{4}$ Cf. Ethica, III, 2, sc. (Todas as referências à Ethica provém da seguinte dição: SPINOZA. Éthique. Tradução de B. Pautrat. Paris: Seuil, 1999).

${ }^{5}$ Cf. Ethica, IV, praef., p. 341.

${ }^{6}$ Ethica I, app., p. 89.

7 COLERUS, J. La vie de B. de Spinoza tirée des écrits de ce fameux philosophe, et du témoignage de plusieurs personnes dignes de foi, qui l'ont connu particulièrement. La Haye: T. Johnson, 1706, p. 59; atualmente também em COLERUS, J. La vie de B. Spinoza. In: SPINOZA. Éthique. Tradução de B. Pautrat. Paris: Seuil, 1999, p. 565. Quanto a considerações sobre a relação de Spinoza com a pintura e os pintores, cf. PIGUET, J.-Cl. Le Dieu de Spinoza. Genève: Labor et fides, 1987, pp. 9-19.

${ }^{8}$ Nesse sentido, ver também MIGNINI, F. Op. Cit.

${ }^{9}$ Ethica, III, def. 2, p. 203.

${ }^{10}$ Ethica, II, 17 sc., p. 137.

${ }^{11}$ Para um estudo da noção de arte em relação com a idéia de método no Tractatus de intellectus emendatione, cf. KLAJNMAN, A. Méthode et art de penser chez Spinoza. Paris: Kimé, 2006.

${ }^{12}$ Cf. Tractatus politicus, cap. V, § 5.0

${ }^{13}$ DANTO, A. The Philosophical Disenfranchisement of Art. Columbia University Press, New York 1986; tradução para o francês, L'assujettissement philosophique de l'art. Paris: Seuil, 1993, p. 23.

${ }^{14}$ Tractatus theologico-politicus, cap. 5. 
${ }^{15}$ Ethica, III, 2 sc. 